\title{
Fatores que contribuíram para a reeleição da presidente Dilma Roussef
}

\author{
Diogo José Dalpoz Martins ${ }^{1}$ \\ Fernanda Helen Mansano ${ }^{2}$ \\ José Luiz Parré ${ }^{3}$ \\ Wander Plassa 4
}

\section{Resumo}

0 presente artigo procura analisar, partir da utilização de métodos de econometria espacial, os principais fatores que levaram à reeleição da presidente Dilma Rousseff nas eleições presidenciais de 2014. Além disso, procura averiguar se a presença de prefeitos e governadores de mesmo partido beneficiou sua candidatura. Os resultados apresentados indicam quea candidata recebeu a maioria dos votos nos municípios menos desenvolvidos, com renda per capita menor, maior taxa de analfabetismo e desemprego, sendo também beneficiada pela presença de governador da mesma coligação. Outro ponto analisado foi, a partir de Regressão Ponderada Geograficamente (RPG), o efeito do programa Bolsa Família em cada município brasileiro. A variável se mostrou estatisticamente significativa, em sua maioria, nos municípios das regiões Sul e Sudeste.

Palavras-chave: Eleições presidenciais; Bolsa Família; Econometria espacial.

\section{Introdução}

A eleição de 2014 em que Dilma Rousseff foi reeleita no segundo turno foi considerada a mais disputada dentre todas as anteriores realizadas no Brasil, levando-a novamente ao cargo de presidente com uma diferença de apenas 3,28 pontos percentuais em relação ao candidato Aécio Neves ${ }^{5}$. Esta disputa acirrada suscitou em algumas discussões a respeito da distribuição dos votos para cada

1 Mestre em economia pela universidade estadual de Maringá (UEM). Email: diogojdmartins90@gmail.com.

2 Mestre em economia pela universidade estadual de Maringá (UEM). Email: fernanda.mansano7@gmail.com.

3 Professor titular do departamento de economia da universidade estadual de Maringá (UEM). E-mail: jlparre@uem.br.

4 Doutorando em economia pela faculdade de Economia, Administração e Contabilidade de Ribeirão Preto - FEA-RP/USP. E-mail: wanderplassa@outlook.com.

5 Dilma Rousseff obteve 51,64\% dos votos, enquanto Aécio Neves 48,36\% (TSE, 2014). 
candidato, relacionadas ao Programa Bolsa Família, ao nível de escolaridade e principalmente pela localidade de residência do eleitor.

Segundo dados do Tribunal Superior Eleitoral (TSE), o resultado da eleição para presidente no segundo turno estabeleceu uma divisão do eleitorado. Grande parte dos municípios em que a presidente eleita foi vencedora estava localizada nas regiões Norte e Nordeste, enquanto que as regiões Sul e Sudeste foram favoráveis ao candidato não-eleito. Já a região Centro-Oeste apresentou uma divisão de votos entre os candidatos.

Dessa forma, o presente artigo teve como objetivo analisar os principais fatores que contribuíram para a reeleição da presidente, partindo das premissas de indícios de correlação espacial no desempenho de cada candidato nos municípios brasileiros. Para se alcançar o objetivo, foi feita uma análise dos dados utilizando o método de econometria espacial para poder levar em consideração a correlação espacial entre a quantidade de votos e os municípios vizinhos. Além de aplicar a metodologia de estimação econométrica local de regressão ponderada geograficamente (RPG) para análise dos efeitos da variável porcentagem da população atendida pelo programa Bolsa Família sobre a população total do município em questão.

Nesse sentido, o artigo em questão foi dividido em cinco seções, a partir dessa introdução, sendo a segunda seção uma revisão de literatura a respeito dos estudos sobre a determinação dos votos presidenciais e as hipóteses sobre a reeleição de Dilma Rousseff. Na terceira seção foi apresentada a metodologia utilizada no trabalho, na seção seguinte os resultados e por fim, na quinta seção as principais conclusões.

\section{Revisão Bibliográfica}

\subsection{Estudos sobre a determinação dos votos presidenciais}

A área de estudo da geografia eleitoral procura identificar os principais determinantes que levam os partidos e candidatos a terem mais votos em determinados locais em comparação com outros, e tem como base a análise de vários elementos que se relacionam. Segundo Terron (2012), estudos relacionados a geografia eleitoral se iniciaram em 1913, com um estudo na França que o pioneiro da sociologia eleitoral, André Siegfried, sugeriu a relação entre tipo de solo e a orientação do voto no norte do país. Ainda hoje entender a preferência dos eleitores é um tema cada vez mais discutido por cientistas políticos. No caso dos economistas, esses partem da suposição de que as pessoas 
racionais reagem com base em incentivos e suas preferências (SHIKIDA et. al., 2009).

Fair (1988) desenvolveu um modelo utilizando variáveis macroeconômicas e procurou prever os resultados das eleições entre os partidos Democrata e Republicano nas eleições para presidente nos Estados Unidos, a partir de dados de 1916 a 1984 . 0 autor verificou que os eleitores tomam sua decisão de voto baseando no ocorrido no passado, sendo entre seis e nove meses para a taxa de crescimento real, e cerca de dois anos para a taxa de inflação.

Para tentar explicar como os indivíduos reagem a incentivos, modelos foram desenvolvidos como ferramentas de análise a partir da preferência dos eleitores baseados em variáveis políticas e econômicas. Utilizando variáveis relacionadas a emprego, Brown e Chappell (1999) elaboraram um modelo de previsão ex post utilizando os dados das eleições presidenciais dos Estados Unidos de 1952 a 1992 e tentaram aplicar este modelo em uma base de dados ex ante para prever os resultados da eleição presidencial de 1996. Já Mach e Jackson (2005) elaboraram um trabalho utilizando variáveis econômicas para verificar a conexão entre emprego, atitude e mudanças nos votos durante a transição para uma economia de mercado, na Polônia.

Além desses estudos em que os eleitores levam em conta o desempenho econômico do país para decidirem seu voto, há trabalhos que procuraram desenvolver modelos que consideram a questão geográfica como uma variável determinante para a decisão do eleitor. Uma literatura mais ampla a respeito das técnicas de econometria espacial é encontrada em estudos sobre as eleições dos Estados Unidos.

Kim et al. (2003) identificaram um padrão espacial nas eleições presidenciais de 1988 a 2000 e verificou que a concentração geográfica do voto entre Democratas e Republicanos aumentou em escala global e regional. Os Republicanos possuíam melhor desempenho nas regiões rurais e ao oeste do país, enquanto os Democratas se destacaram nas regiões à leste e mais urbanas. Wing e Walker (2006) utilizaram técnicas de análise espacial e investigaram os efeitos das características dos indivíduos e da região em que habitam no desempenho dos candidatos à presidência dos Estados Unidos de 2004. Segundo os resultados, houve evidências de aglomerações geográficas dos eleitores norte-americanos. Os candidatos Republicanos se destacaram na região das montanhas e no centro-oeste do país, como também em regiões onde a população é de maioria branca, com formação escolar entre secundária e curso superior não concluído e famílias mais numerosas, as quais acabam por beneficiar os Republicanos. 
Analisando a questão do incubent effect ${ }^{6}$ nas eleições legislativas de 45 estados do Estados Unidos no período de 1968-1989, Uppal (2008) encontrou que o candidato que tenta a reeleição possui grande vantagem, cerca de $30 \%$ maior chance, em comparação com seus adversários, de vencer a próxima eleição e obtêm 5,3 pontos percentuais mais votos que seus concorrentes. Esses resultados foram obtidos por uma pesquisa quase-experimental, tipo de pesquisa que consegue isolar o efeito devido ao "efeito incumbência" de outros fatores, como qualidade do candidato.

Para o Brasil, Shikida et. al. (2009) afirmou que os municípios possuem diversidades culturais e políticas que devem ser levadas em consideração quando for analisar o desempenho de um candidato ou partido em uma eleição nacional. Utilizando métodos de análise espacial, os resultados revelaram que diferentemente das eleições para presidente de 2002, na eleição de 2006 Lula obteve mais votos de municípios menos desenvolvidos no Brasil. Os resultados também evidenciaram que o Programa Bolsa Família não foi fator principal da reeleição de Lula. As variáveis determinantes foram a redução de desigualdade de renda e os ganhos de rendas da população mais pobres, mesmo que grande parte desse cenário possa não ter sido resultado de políticas públicas elaboradas pelo próprio Lula no primeiro mandato.

Terron e Soares (2010) procuraram verificar se existiam um distanciamento da entre Lula e o Partido dos trabalhadores (PT) com base naseleições de 1994-2006 para presidente e para deputados federais pelo PT. A partir do uso de distribuição espacial das votações ao nível do município com mapas, estatísticas e regressões espaciais os autores encontraram um distanciamento entre as bases eleitorais de Lula e do PT, principalmente após as eleições de 2002. 0 então presidente Lula expandiu sua base para as regiões norte e nordeste e o PT permaneceu um partido urbano. Mariani (2010) analisou a existência de clusters de municípios no estado de Santa Catarina, no qual os eleitores possuem a mesma preferência em relação à escolha do candidato à presidência. De acordo com os resultados, houve evidências de dependência espacial na votação dos três principais candidatos na eleição de 2010 (Dilma, Serra e Marina), o que possibilitou a divisão do estado em três zonas de influência.

0 trabalho desenvolvido por Pereira et. al. (2015) apresentou resultados de que o Programa Bolsa Família teve um papel importante

\footnotetext{
6 Vantagem que um candidato, ao tentar reeleição, possui sobre os outros participantes no processo eleitoral. No caso da candidata Dilma Rousseff, ela tomaria vantagem ao representar a situação.
} 
na eleição da candidata Dilma Rousseff em 2010, e se manteve importante mesmo quando levado em conta outras variáveis de cunho econômico, social e político, sendo que a votação mais expressiva na candidata adveio de municípios com menor nível de escolaridade.

Já Lima e Menezes (2015) utilizaram variáveis econômicas e políticas do Brasil para as eleições de 2010 e verificaram que os municípios em que o Partido dos Trabalhadores (PT) foi vitorioso estavam cercados por outros municípios que se comportavam de forma semelhante. Observaram que a presença de um membro do mesmo partido no Poder Legislativo do município acaba gerando um spillover ${ }^{7}$ positivo, enquanto o Poder Executivo (Prefeito) acaba gerando spillover negativo. Esses trabalhos indicaram que a distribuição dos municípios também pode afetar o desempenho eleitoral.

Por fim, Canêdo-Pinheiro (2015) analisando o papel do Programa Bolsa Família e do desempenho econômico na migração da base eleitoral de Lula para regiões menos desenvolvidas, para as eleições presidenciais de 2006, encontrou que a apesar da participação no PBF não resultar em aumento na probabilidade de votos em Lula o programa teve maior impacto que o crescimento econômico. Sendo que o efeito do crescimento econômico teve efeito positivo somente sobre os votos do grupo com maior renda. Apesar desses resultados, o autor concluiu que nem o crescimento econômico nem a massificação do programa Bolsa Família parecem explicar a migração massiva dos votos para candidato da situação de regiões menos desenvolvidas nas eleições presidenciais de 2006.

\subsection{Hipóteses sobre reeleição de Dilma Rousseff}

Antes de mencionar as hipóteses a reeleição da atual presidente, autores como Hunter e Power (2007) desenvolveram um estudo para explicar os motivos da reeleição do presidente Luiz Inácio Lula da Silva, do mesmo partido político de sua sucessora, Dilma Rousseff. Os autores destacaram e dividiram três hipóteses para a eleição de Lula:

1) Os eleitores mais pobres e com nível de escolaridade mais baixo possuem menor acesso a informações a respeito das denúncias e dos escândalos políticos e não repudiam a corrupção tanto quanto os eleitores de maior renda e escolaridade.

2) Os eleitores mais pobres retribuíram a melhoria da sua condição social durante o governo de Lula por meio do voto.

\footnotetext{
7 Efeito transbordamento: em uma análise espacial, o desempenho de um município pode afetar o município vizinho ou próximo.
} 
3) As políticas sociais de transferência direta de renda, como o Programa Bolsa Família (PBF), seria o elemento chave para eleger o presidente.

A partir dessas hipóteses, pode-se averiguar sobre a importância década uma delas na reeleição do ex-presidente. De acordo com o Ministério do Desenvolvimento Social e Combate à Fome (MDS, 2014), o Programa Bolsa Família é um programa de transferência direta de renda para beneficiar famílias em situação de pobreza (renda per capita mensal entre $R \$ 77,01$ e $R \$ 154$ ) ou de extrema pobreza (renda mensal por pessoa de até $\mathrm{R} \$ 77,00^{8}$ ) em todo país. 0 programa é sustentado por três pilares: alívio imediato da pobreza por meio da transferência direta da renda; as condicionalidades que promovem o acesso a direitos sociais básicos de educação, saúde e assistência social; e ações e programas complementares que tem como bjetivo levar a família a superar a situação de vulnerabilidade. 0 benefício mensal varia de acordo com a composição e a situação da família, podendo variar de $\mathrm{R} \$ 35,00$ a $\mathrm{R} \$ 77,00$. Em abril de 2014, pouco mais de 14 milhões de famílias eram beneficiadas, chegando a cerca de 50 milhões de pessoas.

A literatura a respeito do efeito causado pela transferência direta de renda nas eleições é bastante ampla no país, principalmente a partir da reeleição do ex-presidente Lula em 2006. Carraro et al. (2007) procurou encontrar os determinantes da eleição do presidente Lula, dentre eles o Programa Bolsa Família. Porém, em seu trabalho foi verificado o contrário do que se esperava, o Programa Bolsa Família, apesar de ser significante, demonstrou um coeficiente próximo de zero, colocando em dúvida as evidências até então. Já Soares e Terron (2008) avaliaram a mudança no padrão da distribuição dos votos na eleição de Lula, comparando as eleições de 2002 e de 2006 e verificaram que isso se deu principalmente pelos programas de transferência direta de renda, como o Bolsa Família (BF). Para Marques et al. (2009), o Programa Bolsa Família foi de extrema importância para a reeleição do presidente Lula em 2006, pois foi responsável por $45 \%$ do total dos votos recebidos.

Em estudos semelhantes, o trabalho elaborado por Marzagão (2013) para explicar as causas da eleição de Dilma em 2010 inclui algumas outras variáveis além do Bolsa Família, como por exemplo a presença de prefeito do Partido dos Trabalhadores (PT) na época da eleição, PIB (Produto Interno Bruto) per capita, proporção da população analfabeta, população rural e com saneamento básico

\footnotetext{
${ }^{8}$ Valores referentes ao ano de 2014.
} 
inadequado. A utilização de dados a respeito da presença de prefeitos do mesmo partido, ou de partidos da mesma coligação que o candidato à presidência é relevante, visto que estes são apoiados pelos representantes locais. Já em estudos de Cox e McCubbins (1986), os autores relataram que existia uma disputa entre os partidos nas esferas inferiores do governo, no caso o municipal, e as esferas superiores (federal).

\section{Metodologia}

Para o desenvolvimento do modelo de análise o presente trabalho utiliza as três hipóteses já levantadas em trabalhos anteriores e adiciona outras três hipóteses. Desta forma são apresentadas seis hipóteses no total:

1) Os eleitores mais pobres e com nível de escolaridade mais baixa possuem menor acesso a informações a respeito das denúncias e dos escândalos políticos e não repudiam a corrupção tanto quanto os eleitores de maior renda e escolaridade, e isso beneficia o candidato à reeleição (HUNTER E POWER, 2007).

2) Os eleitores mais pobres retribuíram a melhoria da sua condição social por meio do voto (HUNTER E POWER, 2007).

3) As políticas sociais de transferência direta de renda, como o Programa Bolsa Família, seriam o elemento chave para eleger o presidente (COX E MCCUBBINS, 1986).

4) Presença de prefeitos e/ou governadores de mesmo partido ou coligação aumenta as chances de o candidato receber uma quantidade maior de votos (MARZAGÃO, 2013).

5) O baixo crescimento da economia verificado no primeiro governo da presidente Dilma pode ter efeito negativo sobre o número de votos da presidente (MARZAGÃO, 2013).

6) Por fim, o baixo nível de desemprego em um curto período de tempo antecedente à reeleição em comparação às eleições anteriores pôde contribuir de forma positiva (MARZAGÃO, 2013).

\subsection{Dados}

No presente trabalho foram utilizados mapas, análises geográficas e análise de regressão espacial. As análises incluíram dados, a nível municipal, de 5.567 municípios brasileiros, a partir de dados do Tribunal Superior Eleitoral (TSE), do Atlas de Desenvolvimento Humano (Censo 2010) e do Sistema de Benefícios ao Cidadão (SIBEC) da Caixa Econômica Federal para dados do Bolsa Família para 2014. No processo foram utilizados dois softwares em conjunto, o GeoDa 1.6.0 e o ArcMap 10.1. 
Para verificar os determinantes da eleição de 2014, foram acrescentadas outras variáveis baseando-se em trabalhos internacionais e trabalhos nacionais que analisaram eleições no Brasil. Assim, foram selecionadas seis variáveis, a saber, a Taxa de Analfabetismo acima dos 15 anos (T_ANALF15M), a Renda Per Capita (RDPC), a Taxa de Desocupação Acima de 18 Anos (T_DES18M), a Parcela da População Atendida pelo programa Bolsa Família (BOLSAF_POP) e duas variáveis binárias, uma com valor 1 se o candidato eleito a governador do estado é do mesmo partido que o presidente eleito (Partido dos Trabalhadores - PT), e 0 caso contrário (EXEC_EST), e outra que atribui valor 1 caso o prefeito pertença ao partido dos trabalhadores, e 0 caso contrário (EXEC_MUN). ${ }^{9}$

\subsection{Método}

A metodologia de análise é abrangida pela Análise Exploratória de Dados Espaciais (AEDE), que segundo Almeida (2012) é uma técnica utilizada para descrever e visualizar distribuições espaciais, verificar outliers e clusters espaciais, além de auxiliar na especificação do modelo a ser utilizado na análise ${ }^{10}$, a qual foi dividida em três passos.

Assim, o processo de estimação seguiu o procedimento recomendado por Florax et al. (2006), em que se deve estimar o modelo de regressão linear clássico e testar se há autocorrelação espacial. Caso exista, o procedimento para escolher entre os modelos SAR e SEM, será a partir da análise do Multiplicador de Lagrange. Caso o teste para ambos os modelos seja significativo, deverá ser utilizado o Multiplicador de Lagrange Robusto e verificar o maior valor. Um ponto importante a ser abordado antes de implementar as técnicas de AEDE é a definição de uma matriz de pesos espaciais (W), que tem por objetivo capturar os efeitos de contiguidade e vizinhanças sobre os dados. Há na literatura algumas matrizes de pesos espaciais, no entanto, esse

9 As estatísticas descritivas e a matriz de correlação das variáveis pode ser encontrada no apêndice A (tabela A.1 e A.2).

10 Um ponto importante antes da aplicação metodológica foi a correção do número de municípios a partir das bases de dados utilizadas. Na especificação do modelo do Censo de 2010 e do TSE de 2014, foi verificado que entre os dois anos-base houve a criação de alguns municípios, surgindo algumas diferenças. Para corrigir, alguns autores sugerem utilizar o valor da defasagem espacial nos municípios que não possuem dados. Porém, este processo insere autocorrelação espacial nos dados. Então foi utilizada outra técnica, na qual considera o número de municípios menores que $0,5 \%$ do total. Dessa maneira utilizou-se a média das observações do respectivo estado para o município que não possuía dados. 
trabalho utilizará a matriz contiguidade binária do tipo rainha (Queen) ${ }^{11 .}$

Assim, para a aplicação da metodologia, o primeiro passo foi estimar o modelo de regressão linear, por Mínimos Quadrados Ordinários (MQO):

$$
\operatorname{LDILMA}_{i}=\alpha+\beta X_{i}+\delta D_{i}+\varepsilon_{i}
$$

Em que $i=1,2, \ldots, 5567$ municípios; LDILMA $A_{i}$ é o logaritmo natural da percentagem de votos recebidos pela candidata Dilma Rousseff por município $i$ nas eleições de 2014; $X_{i}$ é o vetor das variáveis explicativas logaritmizadas para cada município; $D_{i}$ é o vetor das variáveis binárias; $\alpha$ e $\beta$ são os parâmetros a serem encontrados e $\varepsilon_{i}$ é o termo de erro.

1) 0 vetor $X$ é composto pelos seguintes dados, a nível municipal:

a. Taxa de analfabetismo acima dos 15 anos (T_ANALF15M).

b. Percentagem da população com 25 anos ou mais com nível superior completo (T_SUPER25M).

c. Renda per capita - em R $\$$ de 2010 (RDPC).

d. Taxa de desemprego da população acima dos 18 anos (T_DES18M).

e. Número de famílias atendidas pelo Bolsa Família em Setembro de 2014 em relação à população total do município (BOLSAF_POP).

2) E o vetor $D$ é composto por duas variáveis binárias também a nível municipal:

a. Presença de Executivo municipal do mesmo partido do presidente eleito - valor 1 caso seja do mesmo partido e 0, caso contrário (EXEC_MUN).

b. Presença de Executivo estadual do mesmo partido/coligação do presidente eleito - valor 1 caso seja do mesmo partido e 0 , caso contrário (EXEC_EST).

0 segundo passo foi utilizar a abordagem da econometria espacial, pois quando os dados apresentam efeitos espaciais, ignorá-los tornaria os estimadores viesados e forneceria inferências equivocadas, sendo que dois modelos espaciais foram testados: o modelo de defasagem espacial (SAR) e o modelo de erro espacial (SEM).

Assim, o primeiro modelo é o de defasagem espacial ou Spatial Autoregressive Model (SAR). Esse modelo incorpora um coeficiente autorregressivo espacial, a fim de obter o efeito de "vizinhança" do fenômeno em estudo, que captaria a forma como um fenômeno seria

11 A matriz do tipo Rainha foi a que apresentou maior valor de $I$ de Moran, desta forma foi a escolhida por este artigo. 
propagado pelas regiões próximas. Assim, esse modelo (em notação matricial) pode ser expresso da seguinte forma:

$$
L D I L M A_{i}=\rho W L D I L M A_{i}+\alpha+\beta X_{i}+\delta D_{i}+\xi_{i}
$$

Em que $L D I L M A_{i}$ contem o vetor nx1 de variáveis dependentes; o parâmetro $\rho$ é coeficiente autorregressivo espacial (um escalar); $\mathrm{WLDIMA}_{i}$ o vetor $\mathrm{nx} 1$ de defasagens espaciais para as variáveis dependentes; $X_{i}$ representa a matriz nxk de variáveis explicativas; $\beta$ é o vetor kx1 de coeficientes de regressão e; $\zeta_{i}$ o vetor $n x 1$ de erros aleatórios.

O parâmetro $\rho$, como aponta Almeida (2012), de defasagem espacial tem seu valor situado no intervalo aberto entre -1 e 1 . Caso esse coeficiente for maior que a unidade, a autocorrelação será positiva, Desta forma, altos valores da taxa de homicídios nas regiões vizinhas aumentam o valor da taxa de homicídio na região i. 0 resultado inverso, onde $\rho$ é menor que a unidade, indica que o alto valor da taxa de homicídio nas regiões vizinhas diminui o valor da taxa de homicídio na região i. Se o valor de $\rho$ for não estatisticamente siginificativo não há evidências que haja autocorrelação.

No modelo de erro autorregressivo espacial (SEM) a dependência espacial é residual, devido à estrutura autorregressiva de primeira ordem no termo de erro. Logo, utiliza-se esse modelo quando os efeitos não modelados não podem estar correlacionados com nenhuma variável explicativa da regressão. 0 modelo SEM, auto regressivo de primeira ordem pode ser expresso da seguinte forma:

$$
\begin{aligned}
& \operatorname{LDILMA}_{i}=\alpha+\beta X_{i}+\delta D_{i}+\xi_{i} \\
& \xi_{i}=\lambda W \xi_{i}+\varepsilon_{i}
\end{aligned}
$$

Onde $\lambda$ é o parâmetro do erro auto regressivo; $W \xi_{i}$ é o termo de defasagem espacial dos erros de $\xi_{\text {i, pois }} W \xi_{\text {i }}$ são vizinhos do $\xi$ i. 0 erro de uma dada observação é dado pela média dos erros nas vizinhanças, mais um componente aleatório $\varepsilon$. $W$ é a matriz de peso. Em ambos os modelos foi utilizado o método da máxima verossimilhança para estimar os parâmetros.

0 processo de estimação seguiu o procedimento recomendado por Florax et al. (2006), em que se deve estimar o modelo de regressão linear clássico e testar se há autocorrelação espacial. Caso exista, o procedimento para escolher entre os modelos SAR e SEM, será a partir da análise do Multiplicador de Lagrange. Caso o teste para ambos os 
modelos seja significativo, deverá ser utilizado o Multiplicador de Lagrange Robusto e verificar o maior valor.

Ademais, utilizou o método de regressão ponderada geograficamente (RPG) desenvolvido por um conjunto de trabalhos dos autores Fotheringham, Brunsdon e Charlton ${ }^{12}$ para obter parâmetros para cada unidade espacial local. Esse método, segundo Almeida (2012), considera que dados mais próximos do ponto da regressão têm maior probabilidade de influenciá-lo. 0 objetivo desse método é encontrar respostas (coeficientes estimados) do modelo proposto para cada município brasileiro. 0 modelo RPG é especificado desse modo:

$$
y_{i}=\beta_{0}\left(u_{i}, v_{i}\right)+\sum_{k} \beta_{k}\left(u_{i}, v_{i}\right) x_{i k}+\varepsilon_{i}
$$

Em que $\left(u_{i}, v_{i}\right)$ indica as coordenadas do ponto $i$ no espaço e $\beta_{k}\left(u_{i}\right.$, $v_{i}$ ) é o coeficiente local no ponto $i$. O RPG considera que regiões mais próximas assumem papel mais importante na regressão, atribui pesos maiores para essas regiões, em que essa ponderação é feita pela função Kernel espacial. Assim, foi utilizada a função de ponderação espacial que gere um Kernel adaptativo que se expanda em áreas em que as observações sejam escassas e encolha em áreas em que as observações sejam abundantes, sendo utilizado 30 vizinhos mais próximos como conjunto para a função Kernel.

\section{Análise Espacial e Resultados}

\subsection{Correlação espacial (Índice de Moran)}

O desempenho eleitoral das eleições de 2014 foi ilustrado no Mapa 1, sendo a distribuição dos votos recebidos pela candidata eleita, Dilma Rousseff, no segundo turno das eleições presidenciais, de visualização fácil devido a concentração dos votos em determinadas regiões do país. Os estados da região Nordeste concentram a maioria dos municípios com elevada votação na candidata, sendo também destacado o Estado do Amazonas. Já nos estados da região Sudeste e Sul estavam concentrados os municípios em que a candidata recebeu menos de $50 \%$ dos votos válidos.

Foram divididos cinco grupos para análise da taxa de votos recebidos pela presidente reeleita para os 5567 municípios brasileiros. No primeiro grupo estão aqueles municípios em que, em 2014, a taxa de votos variou de zero a $20 \%$. 0 número de municípios que se encontraram nesse grupo foi de apenas $35(0,62 \%)$, em sua maioria municípios pertencentes a região sul e sudeste do Brasil. 0 segundo

\footnotetext{
12 Brunsdon, Fotheringham e Charlton (1998, 1999, 2003).
} 
grupo em que se encontra os municípios que apresentaram taxas de votos recebidos por Dilma entre 20,01\% e 40\% estão um total de 1017 municípios, o que representa $18,27 \%$ do total de municípios brasileiros. No terceiro grupo pode-se verificar os municípios que exibiram taxas de votos entre $40,01 \%$ e $60 \%$. 0 número de municípios que compõe esse grupo é de 1995 (35,83\% do total).

\section{Mapa 1. Distribuição dos votos para a candidata Dilma por município nas eleições presidenciais de 2014.}

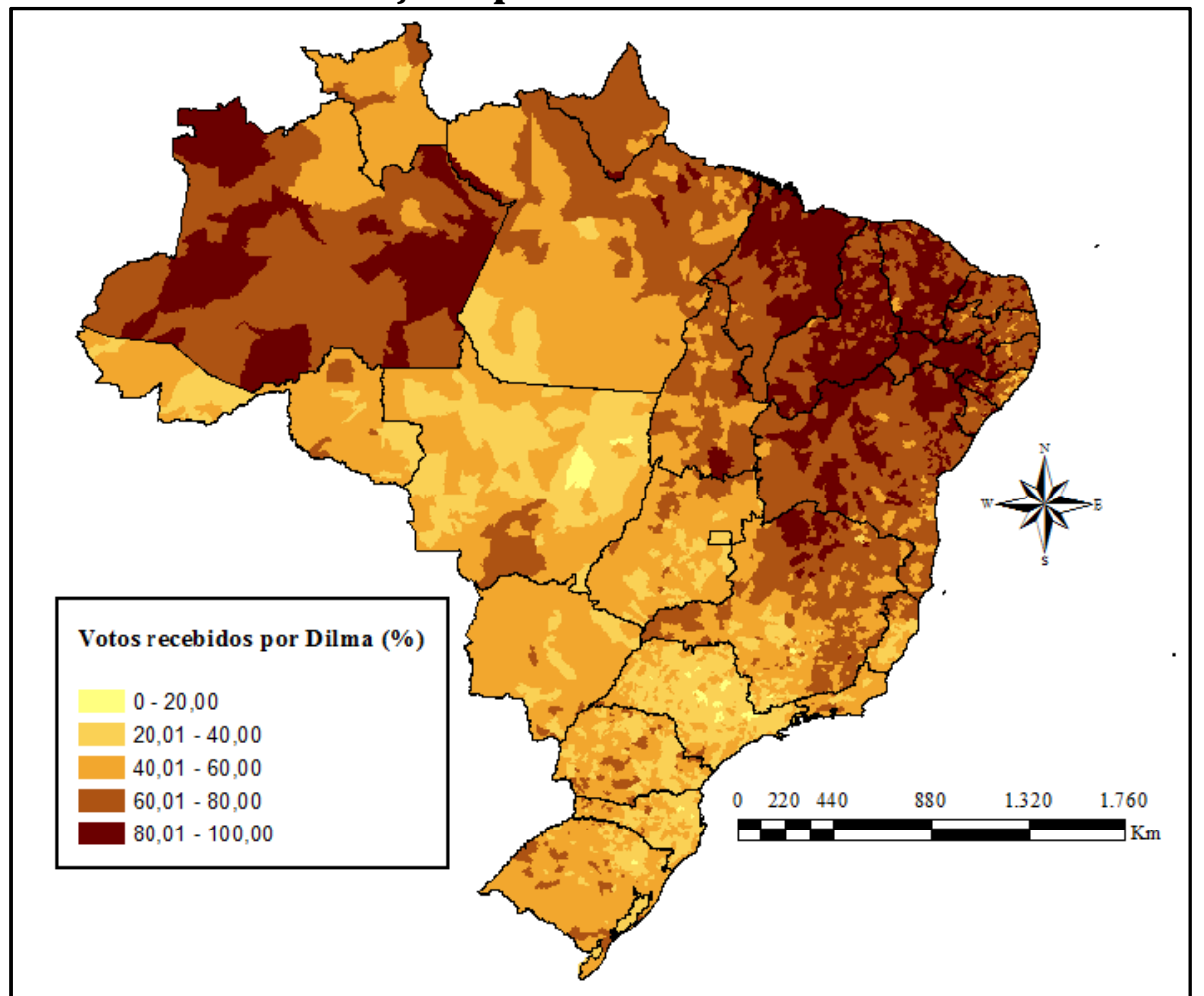

Fonte: Tribunal Superior Eleitoral (TSE, 2014)

Nota: Percentual de votos no Segundo turno das eleições.

Nos dois últimos grupos estão aqueles municípios que apresentaram uma taxa de voto da presidente reeleita acima de $60 \%$. 0 número de municípios que se encontraram no grupo de 60,01 a $80 \%$ chegou a $1740(31,26 \%)$ e, por fim, o número de municípios em que essa taxa superou os $80 \%$ foi de $780(14,02 \%)$, em sua maioria em municípios da região norte (Amazonas e região Norte do Pará) e nordeste do Brasil.

Para verificar melhor a distribuição espacial dos votos em 2014, foi realizada uma análise do diagrama de dispersão do Gráfico $1 \mathrm{e}$ os clusters com o I de Moran local do Mapa 2. 0 diagrama de dispersão de Moran apresenta, no eixo das abscissas, o valor da variável de interesse, no caso a percentagem de votos recebida pela candidata 
Dilma por município e, no eixo das ordenadas, a defasagem espacial desta mesma variável. Vale lembrar que tanto a variável de interesse quanto a defasagem espacial são padronizadas, possuem média zero e variância unitária (ALMEIDA, 2012).

Assim, o valor do I de Moran que possibilita verificar a autocorrelação espacial dos resíduos da regressão apresentado, foi de 0,8534 e rejeitou-se a hipótese nula, ou seja, os resíduos são autocorrelacionados especialmente com menos de $1 \%$ de significância. Além disso, o critério de vizinhança utilizado foi o de contiguidade, ou seja, são considerados vizinhos os municípios que compartilham de uma fronteira em comum. Assim, os municípios que tiveram valores acima da média e vizinhos de outros também com valores acima da média, ocuparam o primeiro quadrante do diagrama. Com relação aos municípios abaixo da média, com vizinhos na mesma situação, foram localizados no terceiro quadrante. 0 quarto e o segundo quadrante representam os municípios "ilhas", pois possuem observações acima da média e são cercados de municípios abaixo da média, e vice-versa. Caso não houvesse correlação espacial, os pontos do diagrama estariam distribuídos no quarto quadrante. $O$ valor do $I$ de Moran de 0,8534 apresentado no Gráfico 1 ajudou a verificar que a hipótese de ausência de correlação espacial foi rejeitada com menos de 1\% de significância.

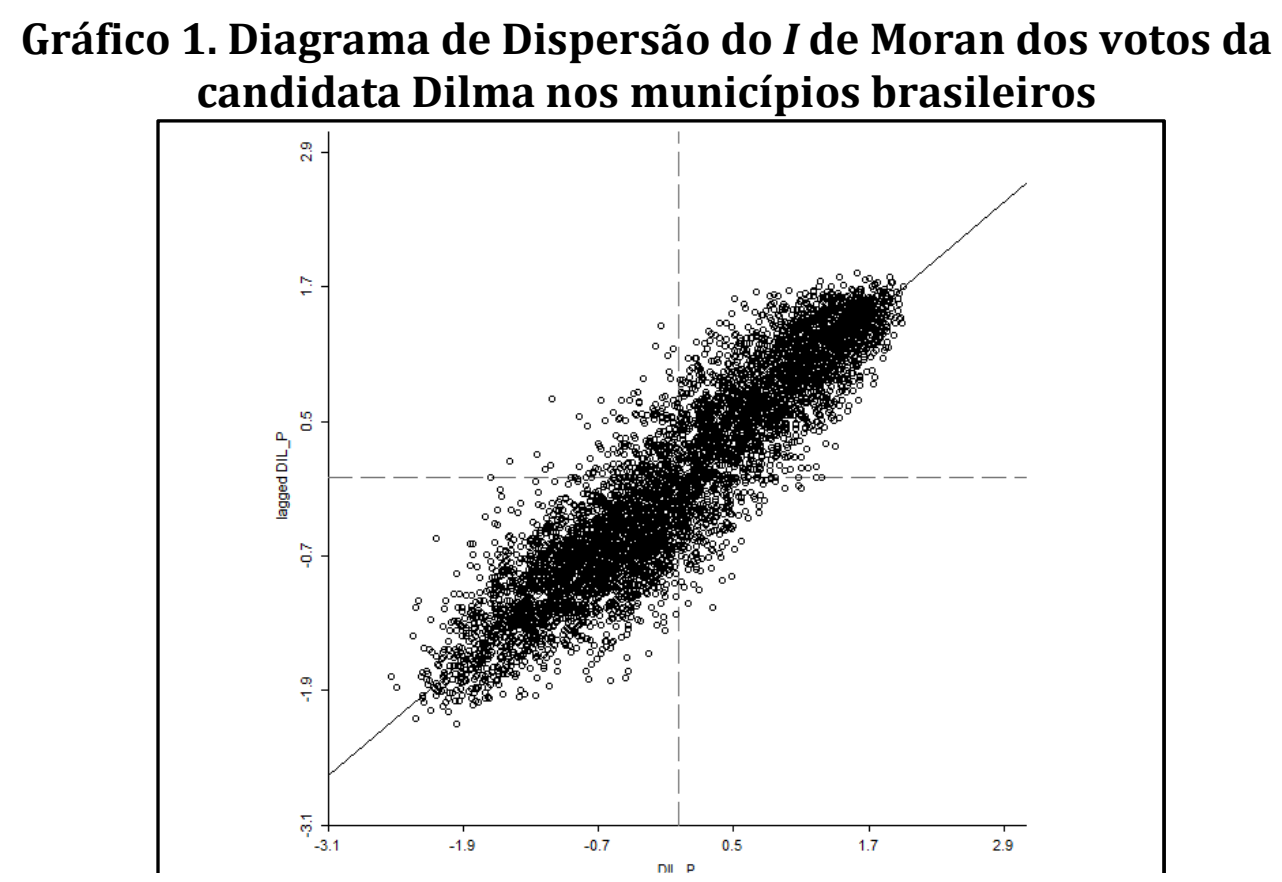

Fonte: Elaboração dos autores a partir de TSE, 2014.

Nota: Percentual de votos no Segundo turno das eleições.

Para a percepção do padrão espacial, o I de Moran Local destacou os municípios em que houve clusters estatisticamente 
significativos com valores alto-alto e baixo-baixo. 0 Mapa 2 demonstra a aglomeração de municípios Alto-Alto (1018 observações) localizados principalmente na região Nordeste e no estado do Amazonas, enquanto os valores Baixo-Baixo estão no Sudeste e Sul do país e no estado do Mato Grosso (1179 observações). A parte sem cor corresponde aos municípios que não foram significativos (3370 observações).

Um fato interessante, identificado no Mapa 2, foi a não constatação de municípios que foram estatisticamente significativos e classificados como Alto-Baixo e Baixo-Alto, isto é, dos municípios chamados "ilhas". Isto demonstra a importância da análise espacial para o tema, uma vez que no Brasil, a eleição de 2014 mostrou uma clara e significativa divisão dos votos entre as regiões em que municípios que votaram e média mais em um candidato eram rodeados por outros municípios com a mesma característica.

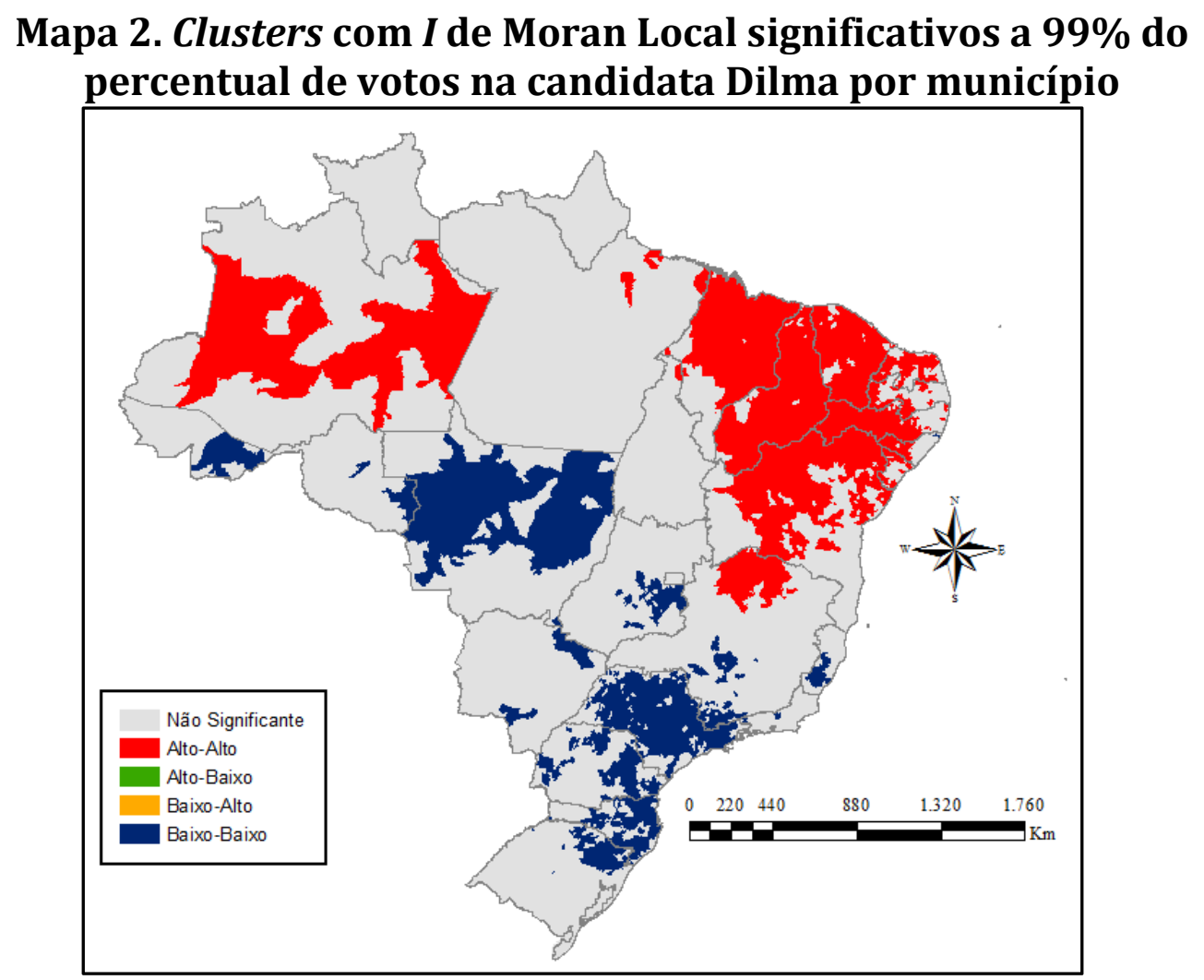

Fonte: Elaboração dos autores

Na Tabela 1 são apresentadas as médias de cinco variáveis, a saber, taxa de analfabetismo, percentual com 25 anos ou mais com ensino superior completo, renda per capita, taxa de desemprego para pessoas acima de 18 anos e percentual das pessoas que participam do Programa Bolsa Família para os municípios que formaram os clusters Alto-Alto e Baixo-Baixo. 
Tabela 1. Classificação das variáveis utilizadas segundo o I de Moran Local

\begin{tabular}{|c|c|c|}
\hline & Alto-Alto & Baixo-Baixo \\
\hline Municípios & 1179 & 1018 \\
\hline $\begin{array}{c}\text { Taxa de Analfabetismo (\%) } \\
\text { \% com 25 ou mais com } \\
\text { superior completo }\end{array}$ & 27,32 & 7,23 \\
$\begin{array}{c}\text { Renda Per Capita (R\$) } \\
\text { Taxa de Desemprego } \\
\text { Acima 18 Anos (\%) }\end{array}$ & 257,18 & 8,17 \\
\hline \% População Bolsa Família & 7,77 & 747,51 \\
\hline
\end{tabular}

Fonte: Elaboração dos autores.

Verificou-se na Tabela 1 que nos 1179 municípios classificados como Alto-Alto em que a candidata Dilma Rousseff recebeu mais votos, a percentagem média da taxa de analfabetismo foi de 27,32. Valor consideravelmente inferior foi observado nos 1018 municípios classificados como Baixo-Baixo, onde o candidato concorrente obteve maior destaque, cerca de $7 \%$. Outra variável relacionada à escolaridade, percentagem de 25 ou mais anos com superior completo, também seguiu o mesmo padrão. A média para os municípios do agrupamento Alto-Alto foi de 3,37\%, contrastando com a média de $8,17 \%$ dos municípios do agrupamento Baixo-Baixo.

A renda per capita média entre esses dois grupos também apresentou valores médios bem diferentes, em que a renda média nos municípios Alto-Alto não chega a $\mathrm{R} \$ 260,00$, enquanto, para os municípios classificados como Baixo-Baixo, essa renda per capita média foi de $\mathrm{R} \$ 747,51$. A taxa de desemprego, em contrapartida, atinge valores mais altos nos clusters Alto-Alto, 7,77\%.

Por fim, é apresentadaa percentagem da população atendida pelo Programa Bolsa Família nos municípios classificados como Alto-Alto e Baixo-Baixo. Nos municípios que formam o cluster Alto-Alto a percentagem da população que contemplada pelo Programa Bolsa Família foi de 17,29. Uma diferença considerável pode se notar para os municípios que formam os clusters Baixo-Baixo, 3,61\%. Inicialmente, isto confirma as hipóteses iniciais do modelo, resta saber, a partir dos resultados da regressão, se esses coeficientes são significativos. 


\subsection{Resultados Econométricos}

Devido às características demonstradas na seção anterior sobre o Indicador de Moran e os clusters espaciais formados, no Modelo de Erro Espacial (SEM), a dependência espacial está nos resíduos, ou seja, o padrão espacial manifestado no termo de erro é causado por efeitos que não foram adicionados ao modelo. Cabe ressaltar que os efeitos não modelados não podem estar correlacionados com as variáveis explicativas da regressão. Neste modelo, $\lambda$ é um escalar do termo de erro, $\varepsilon_{i}$ segue uma distribuição normal com média zero e variância $\sigma^{2} \mathrm{I}$ e W é a matriz de pesos espaciais (binária de vizinhança) utilizada para calcular o I de Moran.

A Tabela 2 ilustra os resultados da estimação dos parâmetros a partir do modelo de regressão linear clássico, conforme proposto por Florax et al. (2006). Os resultados indicam que os determinantes da votação em Dilma no ano de 2014 são todos inelásticos. Com destaque para duas delas:

1) a renda per capita possui coeficiente negativo e, portanto, demonstra uma relação inversa com os votos recebidos. Uma variação de $1 \%$ na renda per capita do município reduz em $0,223 \%$ a votação da candidata.

2) o coeficiente referente a percentagem da população atendida pelo Programa do Bolsa Família apresentou um parâmetro de 0,159. Nesse caso, um aumento em $1 \%$ a parcela da população beneficiada, a candidata aumentará seus votos em 0,159\%.

Também foi verificado na Tabela 2 que os testes de diagnóstico para autocorrelação espacial foram satisfatórios no modelo clássico, indicando que é aconselhável utilizar modelos econométricos espaciais. Quanto à escolha do modelo, foi utilizado o Modelo de Erro Espacial, pois mesmo que ambos os Multiplicadores de Lagrange tenham dados significativos, o valor do LM Robusto para Erro Espacial foi substancialmente maior do que para defasagem. 
Tabela 2. Determinantes de Votos da candidata Dilma por município em 2014 (Modelo de Regressão Linear Clássico)

\begin{tabular}{|c|c|c|c|}
\hline & Coeficiente & Testes & \\
\hline \multirow[t]{2}{*}{ Constante } & $4,954^{* * *}$ & $\mathrm{R}^{2}$ & 0,635 \\
\hline & $(0,0000)$ & Teste F & 1382,77 \\
\hline \multirow[t]{2}{*}{ Taxa de Analfabetismo (\%) } & $0,031^{* * *}$ & Log Likehood & 783,59 \\
\hline & $(0,0014)$ & $\begin{array}{l}\text { Critério de Akaike } \\
\text { Information }\end{array}$ & $-1551,18$ \\
\hline \multirow[t]{2}{*}{$\begin{array}{l}\% \text { de } 25 \text { ou mais com superior } \\
\text { completo }\end{array}$} & $-0,022^{* * *}$ & $\begin{array}{l}\text { Critério de Schwarz } \\
\text { Information }\end{array}$ & $-1498,19$ \\
\hline & $(0,0061)$ & LM (erroespacial) & $\begin{array}{l}4244,73^{* *} \\
*\end{array}$ \\
\hline \multirow[t]{2}{*}{ Renda Per Capita (R\$) } & $-0,223^{* * *}$ & & $(0,0000)$ \\
\hline & $(0,0000)$ & LM (defasagem) & $846,69 * * *$ \\
\hline \multirow[t]{2}{*}{$\begin{array}{l}\text { Taxa de Desemprego Acima } \\
18 \text { Anos (\%) }\end{array}$} & $-0,004$ & & $(0,0000)$ \\
\hline & $(0,3891)$ & LM Robusto (erroespacial) & $\begin{aligned} 3412,79 * * \\
*\end{aligned}$ \\
\hline \multirow[t]{2}{*}{ \% População Bolsa Família } & $0,159 * * *$ & & $(0,0000)$ \\
\hline & $(0,0000)$ & LM Robusto (defasagem) & $14,75^{* * *}$ \\
\hline \multirow[t]{2}{*}{ Presença Executivo Municipal } & $0,017^{* *}$ & & $(0,0001)$ \\
\hline & $(0,0028)$ & & \\
\hline Presença Executivo Estadual & $\begin{array}{r}0,065^{*} \\
(0,0000)\end{array}$ & & \\
\hline
\end{tabular}

Fonte: Elaboração dos autores.

Nota: Os p-valores estão entre parênteses. A notação para a significância estatística em todas as tabelas é: ${ }^{* * *}$ significativo ao nível $1 \%$; ${ }^{* *}$ significativo ao nível de $5 \%$; * significativo ao nível de $10 \%$. 
Tabela 3. Determinantes de Votos da candidata Dilma por município em 2014 (Modelo de Erro Espacial - SEM)

\begin{tabular}{|c|c|c|c|}
\hline & Coeficiente & Testes & \\
\hline \multirow[t]{2}{*}{ Constante } & $3,38^{* * *}$ & $\mathrm{R}^{2}$ & 0,832 \\
\hline & $(0,0000)$ & & \\
\hline \multirow[t]{2}{*}{ Taxa de Analfabetismo (\%) } & $0,076^{* * *}$ & Log Likehood & 2495,50 \\
\hline & $(0,0000)$ & $\begin{array}{l}\text { Critério de Akaike } \\
\text { Information }\end{array}$ & $-4974,99$ \\
\hline \multirow[t]{2}{*}{$\begin{array}{l}\% \text { de } 25 \text { ou mais com superior } \\
\text { completo }\end{array}$} & $-0,011^{*}$ & $\begin{array}{l}\text { Critério de Schwarz } \\
\text { Information }\end{array}$ & $-4921,99$ \\
\hline & $(0,0900)$ & & \\
\hline \multirow[t]{2}{*}{ Renda Per Capita (R\$) } & $-0,127^{* * *}$ & & \\
\hline & $(0,0000)$ & & \\
\hline \multirow{3}{*}{$\begin{array}{l}\text { Taxa de Desemprego Acima } 18 \\
\text { Anos (\%) }\end{array}$} & & & \\
\hline & $0,014^{* * *}$ & & \\
\hline & $(0,0005)$ & & \\
\hline \multirow[t]{2}{*}{ \% População Bolsa Família } & $0,084^{* * *}$ & & \\
\hline & $(0,0000)$ & & \\
\hline \multirow[t]{2}{*}{ Presença Executivo Municipal } & $-0,011^{* * *}$ & & \\
\hline & $(0,0038)$ & & \\
\hline \multirow[t]{2}{*}{ Presença Executivo Estadual } & $0,669^{* * *}$ & & \\
\hline & $(0,0000)$ & & \\
\hline \multirow[t]{2}{*}{$\lambda$} & $0,782^{* * *}$ & & \\
\hline & $(0,0000)$ & & \\
\hline
\end{tabular}

Fonte: Elaboração dos autores.

Nota: Os p-valores estão entre parênteses. A notação para a significância estatística em todas as tabelas é: ${ }^{* * *}$ significativo ao nível $1 \%$; ${ }^{* *}$ significativo ao nível de $5 \%$; * significativo ao nível de $10 \%$.

Nesse sentido, a partir dos dados da Tabela 3 foram apresentados os resultados da estimação pelo Modelo de Erro Espacial (SEM) com as mesmas variáveis utilizadas no Modelo Clássico. 0 coeficiente de correlação $\left(\mathrm{R}^{2}\right)$ aumentou no modelo de estimação SEM, apresentando um melhor ajustamento do modelo. Praticamente todas as variáveis se mantiveram inelásticas e com o mesmo sinal, com exceção para a variável "Presença de Executivo Municipal", que era positivo no modelo clássico e passou a ser negativo no SEM, sendo ambos significativos. Zucco (2008) obteve os mesmos resultados para eleições de 2006, quando o candidato analisado era Luiz Inácio Lula da Silva, também pertencente ao Partido dos Trabalhadores. A presença de prefeitos do mesmo partido do candidato teve efeito negativo sobre os votos de Lula. 0 destaque foi para a variável "Presença de Executivo Estadual", que aumentou o coeficiente de 0,065 no modelo clássico para 0,669 no modelo SEM.

Dessa forma, nos Estados em que a candidata compartilhava do mesmo partido político do governador eleito, em média, seus votos 
foram 0,669\% maiores. Já a variável de "Taxa de desemprego acima de 18 anos", que não era significativa no modelo clássico, passou a ser significativa no modelo de erro espacial, apresentando um coeficiente positivo de 0,014 . A variável percentagem da população atendida pelo Programa Bolsa Família continua a apresentar sinal positivo, porém menor, indicando, como já foi levantado por outros autores (por exemplo, Zucco (2008) para a eleição de 2006 e Pereira et. al. (2015) para eleição presidencial de 2010) que o efeito Bolsa família foi positivo e significativo para afetar a taxa de votos recebidos pela candidata do Partido dos Trabalhadores no ano de 2014.

0 valor de $\lambda$ encontrado no modelo SEM demonstra a dependência espacial residual em 0,782 , indicando que existem efeitos não modelados que devem ser levados em consideração e que são importantes determinantes na distribuição de votos dos candidatos.

Após encontrar os efeitos do Programa Bolsa Família sobre a taxa de votos recebidos pela candidata reeleita à presidência o artigo buscou encontrar quais foram os municípios que se apresentaram estatisticamente significativos para a variável Bolsa Família. Desta forma aplicou-se a técnica de regressão ponderada geográfica (RPG), em que os resultados são apresentados mapa 3:

\section{Mapa 3 - Valores significativos a 5\% da variável população contemplada pelo Programa Bolsa Família}

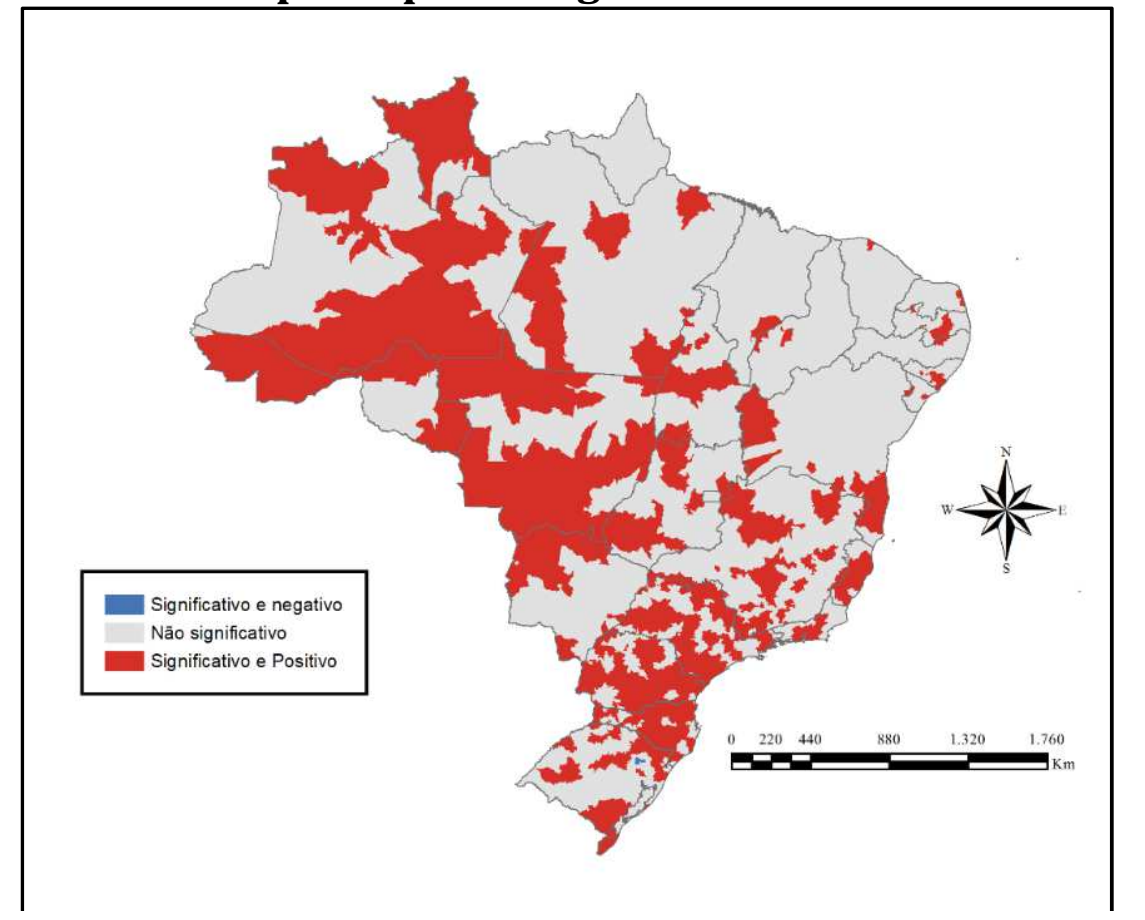

Fonte: Elaboração dos autores.

Nota: teste de significância realizado a partir do valor $\mathrm{t}$ calculado para $5 \%$. 
Na cor vermelha e azul estão os municípios em que a variável "Bolsa Família" foi significativa ao afetar a taxa de votos recebidos pela presidente reeleita. Os coeficientes positivos, isto é, aqueles municípios em que a distribuição do Bolsa Família se mostrou significativo e positivamente relacionado com o número de votos da presidente reeleita estão em vermelho. Pode-se observar que, ao comparar com o mapa 1 que apresenta a distribuição de votos recebidos pela candidata Dilma nos municípios brasileiros, que esses municípios estão localizados, em sua maioria, nas regiões onde a mesma não recebeu uma percentagem alta de votos, principalmente nas regiões Sul e Sudeste do país.

Apesar de apresentarem uma proporção elevada de votos para a candidata reeleita, assim como uma percentagem elevada da População atendida pela Bolsa Família, as regiões Norte e Nordeste não apresentaram um número elevado de municípios estatisticamente significativos para a variável Bolsa Família, principalmente municípios da região Nordeste.

Por fim, os municípios identificados pela cor azul quase não aparecem no mapa, indicando que o efeito Bolsa família, de forma geral, é positivo sobre o número de votos recebidos pela candidata reeleita pelo Partido dos Trabalhadores. Apesar da base do PT permanecer urbana, os candidatos a presidentes desse partido, Lula e Dilma Rousseff, continuam com suas bases nas regiões menos desenvolvidas, principalmente nas regiões norte e nordeste (TERRON e SOARES, 2010; MARZAGÃO, 2013). Essas regiões, por motivos próprios do foco do programa Bolsa Família, que aparecem com os maiores percentuais da sua população atendida pelo mesmo.

Na tabela 4 são apresentadas as características dos municípios que foram estatisticamente significativos e positivos, segundo a Regressão Ponderada Geograficamente apresentada no mapa 3, ao afetar a taxa de votos recebidos por Dilma.

No total 1883 municípios brasileiros foram considerados estatisticamente significativos na eleição de 2014. Nesses municípios o programa Bolsa Família foi significativo ao afetar a taxa de votos da Dilma. São cidades que possuem taxa de analfabetismo menor que a média brasileira, renda per capita superior à média brasileira, porém percentagem de famílias beneficiadas pelo programa Bolsa Família inferior à média.

Nos municípios em que o efeito Bolsa Família não foi significativo, no total 3677 municípios, a taxa média de analfabetismo é superior à do Brasil e bem superior à média dos municípios 
significativos. 0 mesmo padrão foi identificado na questão da renda per capita em que a média nesses municípios foi inferior tanto a média do Brasil quanto a média dos municípios significativos. Por fim, a taxa da população de beneficiadas pelo Bolsa família também foi superior as dos municípios significativos.

Tabela 4. Classificação dos municípios segundo a Regressão Ponderada Geograficamente (RPG)

\begin{tabular}{|c|c|c|c|}
\hline 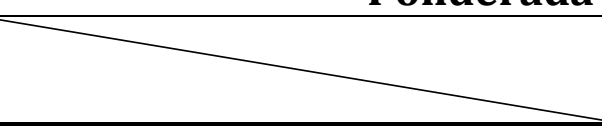 & \begin{tabular}{|c} 
Estatísticamente \\
Positivos
\end{tabular} & $\begin{array}{c}\text { Não } \\
\text { Significativos }\end{array}$ & $\begin{array}{c}\text { Média do } \\
\text { Brasil }\end{array}$ \\
\hline Municípios & 1883 & 3677 & 5567 \\
\hline Taxa de Analfabetismo (\%) & 11,35 & 18,62 & 16,15 \\
\hline $\begin{array}{l}\text { \% com } 25 \text { ou mais com } \\
\text { superior completo }\end{array}$ & 3,82 & 4,09 & 4,00 \\
\hline Renda Per Capita (R\$) & 593,39 & 441,90 & 493,74 \\
\hline $\begin{array}{c}\text { Taxa de Desemprego Acima } \\
18 \text { Anos }(\%)\end{array}$ & 5,34 & 6,64 & 6,20 \\
\hline \% População Bolsa Família & 7,05 & 11,64 & 10,08 \\
\hline
\end{tabular}

Fonte: Elaboração dos autores.

Nota: sete municípios apresentaram valores negativos e estatísticamente significativos.

Os resultados do mapa 3 e tabela 4 indicam que os efeitos estatisticamente significativos e positivos para a reeleição candidata Dilma com relação ao programa Bolsa Família não se deram em municípios menos desenvolvidos como se esperava. Uma explicação para esse fato seria que a população residente nessas regiões pode estar votando em candidatos do Partido dos Trabalhadores independentemente de serem participantes ou não do programa. Essas pessoas podem ter escolhido votar na presidente reeleita por constatarem uma melhora de vida (comércio, saúde e educação, por exemplo) em suas cidades nos últimos anos por conta da renda transferida para essas regiões e não propriamente por serem participantes diretamente do programa. 0 que pode não ser percebido por regiões mais desenvolvidas do Brasil (regiões Sul e Sudeste) onde pode ocorrer uma diferença, em média, no voto entre pessoas que participam e não participam do Programa Bolsa Família. Ou mesmo, como aponta Zucco (2008) que candidatos a reeleição possuem melhor desempenho em regiões mais pobres, o efeito do PBF pode ter sido mitigando nessas regiões e não nas mais desenvolvidas. Contudo, as interpretações devem ser analisadas com cautela uma vez que esses resultados podem ser decorrentes de colinearidade entre o PBF e as 
outras variáveis incluídas no modelo, alterando, assim, os sinais dos coeficientes. ${ }^{13}$

\section{Conclusões}

De acordo com os resultados obtidos, a votação da presidente Dilma no segundo turno das eleições para presidente em 2014 foi maior nos municípios de renda per capita mais baixa, com maior parcela da população analfabeta, com maiores taxas de desemprego e onde o Programa Bolsa Família beneficia um número maior de pessoas.

Voltando às hipóteses iniciais de Hunter e Power (2007), a premissa de eleitores mais pobres e com nível de escolaridade mais baixa acabaram beneficiando a candidata pode ser confirmada de acordo com os resultados encontrados no modelo de erro espacial estimado, em que apresentou um coeficiente negativo de $-0,011$ para a parcela da população com nível superior, significativo a $10 \%$ e um valor positivo de 0,076 para a taxa de analfabetismo acima dos 15 anos, significativo a $1 \%$, podendo-se afirmar que quanto maior o nível de escolaridade, menor foi a quantidade de votos para a candidata Dilma nas eleições de 2014.

Outra questão foi relacionada à hipótese que com a melhora na condição social dos eleitores mais pobres a partir da aplicação do Programa Bolsa Família, esses eleitores direcionariam seus votos na candidata Dilma. Porém, um valor de $\lambda$ de 0,782 , não confirma a hipótese de que o Programa foi o elemento chave para eleger a presidente, pois indica que existem outras variáveis que não fizeram parte do modelo e que colaboram para sua reeleição.

Já a presença de prefeitos do mesmo partido ou coligação que a candidata, não beneficiou sua candidatura. Acreditava-se que estes deveriam apoiar seus parceiros de coligação, evitando uma competição entre partidos, caso o concorrente tivesse ganhado (COX E MCCUBBINS, 1986). No entanto, nos Estados em que o governador eleito compartilhava a mesma coligação que a presidente reeleita, foi um quesito positivo nos votos da candidata.

Por fim, a partir do método de Regressão Ponderada Geograficamente, se pode constatar que a percentagem de pessoas contempladas pelo Bolsa Família foi mais significativo em municípios da região Sul e Sudeste do Brasil, mostrando a importância do programa para obtenção de votos em municípios dessa região, o que

${ }^{13}$ A tabela A.2, exposta no apêndice deste artigo apresenta a correlação entre as variáveis utilizadas na pesquisa. 
pode ter contribuído na reeleição da candidata Dilma Rousseff em 2014.

Assim, pode-se concluir que os principais fatores que levaram à reeleição da presidente Dilma Roussef nas eleições presidenciais de 2014 estavam positivamente relacionados aos municípios com características sociais aquém daqueles que não a elegeram, podendo ainda verificar os resultados de uma variável em especial referente ao percentual dos eleitores que recebem o Bolsa Família a qual apresentou um comportamento esperado, contudo em regiões onde a percentagem de votos recebido pela candidata eleita foi inferior ao do seu adversário.

\section{Referências}

ALMEIDA, E. Econometria Espacial Aplicada. Editora Alínea, 2012.

LIMA, R. C. Andrade; MENEZES, T. A. Uma análise espacial das eleições presidenciais brasileiras de 2010. Pesquisa e Planejamento Econômico, v. 45, n. 3, p. 557-583.2015.

BROWN, L.B.; CHAPPELL, H.W. Forecasting presidential elections using history and polls. International Journal of Forecasting, v.15, n.2, p.127135. 1999.

CANÊDO-PINHEIRO, M. Bolsa Família ou desempenho da economia? Determinantes da reeleição de Lula em 2006. Economia Aplicada, v. 19, n. 1, p. 31-61, 2015.

COX, G. W.; MCCUBBINS, M. D. Electoralpolitics as a redistributive game. Journal of Politics, v. 48, n. 2, p. 370-389, 1986.

FAIR, R. C. The effect of economic events on votes for president: 1984 update. Political Behavior, v. 10, n. 2, p. 168-179, 1988.

FOTHERINGHAM, S.; CHARLTON, M.; BRUNSDON, C. Geographically weighted regression: a natural evolution of the expansion method for spatial data analysis. Environment and planning, v. 30, n. 11, p. 1905-1927, 1998.

Some notes on parametric significance tests for geographically weighted regression. Journal of Regional Science, v. 39, n. 3, p. 497-524, 1999.

Geographically weighted regression: the analysis of spatially varying relationships.John Wiley \& Sons, 2003.

FLORAX, R. J. G. M.; FOLMER, H.; REY, S. J. A Comment on Specification Searches in Spatial Econometrics: The Relevance of Hendry's Methodology: A Reply. Regional Science and Urban Economics, v.36, n.2, Mar., p.300-308. 2006.

HUNTER, W.; POWER, T. Rewarding Lula: Executive Power, Social Policy, and the Brazilian Elections of 2006. Latin American Politics \& Society, v.49, p.130. 2007. 
KIM, J.; ELLIOTT, E.; WANG, D. A Spatial analysis of county-level outcomes in US Presidential elections: 1988-2000. Electoral Studies, n.22, p.741-761. 2003.

MACH, B., J. J. E. Employment Change, Attitude Evolution and Voting During Poland's Transition: Longitudinal Evidence from 1988 to 1998. European Journal of Political Economy. 2005.

MARIANI, C. G. A. Aplicações da Econometria Espacial ao Resultado da Eleição Presidencial de 2010 em Santa Catarina. Associação de Pesquisadores em Economia Catarinense, 2010.

MARZAGÃo, T. A dimensão geográfica das eleições brasileiras. Opinião Pública, v. 19, n. 2, p. 270-290, 2013.

MINISTÉRIO DO DESENVOLVIMENTO SOCIAL E COMBATE À FOME (MDS). Bolsa Família: o que é. 2014. Disponível em <http://www.mds.gov.br/programas/transferencia-de-renda/programabolsa-familia/programabolsa-familia/o-que-e>. Acesso em: 19 nov. 2014.

PEREIRA, A. E. G.; SHIKIDA, C. RIBEIRO F. G.; NAKABASHI, L. A eleição de Dilma em 2010 e seus determinantes: evidências empíricas do programa bolsa família. Análise Econômica, v. 33, n. 64, p. 111-142. 2015.

SISTEMAS DE BENEFÍCIO AO CIDADÃO (SIBEC). Disponível em $<$ https://www.beneficiossociais.caixa.gov.br/consulta/beneficio/04.01.0000_00.asp/>. Acessoem: 19 nov. 2014.

SHIKIDA, C. D.; MONASTERIO, L. M.; ARAUJO Jr, A. F.; CARRARO, A.; DAMÉ, O. M. It is the Economy, Companheiro!: An Empirical Analysis of Lula's Reelection Based on Municipal Data. Economics Bulletin, v. 29, n. 2, p. 976991, 2009.

SOARES, G. A.D.; TERRON, S. L. Dois Lulas: a geografia eleitoral da reeleição (explorando conceitos, métodos e técnicas de análise geoespacial). Opinião Pública, v. 14, n. 2, p. 269-301, 2008.

TERRON, S. L.; SOARES, G. A. D. As bases eleitorais de Lula e do PT: do distanciamento ao divórcio. Opinião Pública, v. 16, n. 2, p. 310-337, 2010.

TERRON, S. Geografia Eleitoral em foco. Revista Em Debate, v. 4, n. 2, p. 8$18,2012$.

TRIBUNAL SUPERIOR ELEITORAL (TSE). Centro de Divulgação da Justiça Eleitoral 2014. Disponível em

<http://www.tse.jus.br/eleicoes/estatisticas/estatisticas-eleitorais-2014eleitorado/>. Acessoem: 19 nov. 2014.

UPPAL, Y. Estimating incumbency effects in us state legislatures: a quasi-experimental study. Economics \& Politics, v. 22, n. 2, p. 180-199, 2010.

WING, I.S.; WALKER, J.The 2004 Presidential Election From A Spatial Perspective. 2006. Disponível em

<http://people.bu.edu/isw/papers/the_2004_election.pdf>. Acessoem: 18 de novembro de 2014. 
ZUCCO, C. The president's 'new'constituency: Lula and the pragmatic vote in Brazil's 2006 presidential elections. Journal of Latin American Studies, v. 40, n. 01, p. 29-49, 2008.

When payouts pay off: Conditional cash transfers and voting behavior in Brazil 2002-10. American Journal of Political Science, v. 57, n. 4, p. 810822, 2013.

\section{APÊNDICE}

Tabela A.1. Definição das variáveis e estatísticas descritivas

\begin{tabular}{|c|c|c|c|c|c|}
\hline Variáveis & Definição & Média & $\mathrm{DP}$ & Mínimo & Máximo \\
\hline DIL_P & $\begin{array}{l}\text { Proporção de votos recebidos pela candidata } \\
\text { Dilma Rousseff }\end{array}$ & 57,71 & 18,10 & 1,00 & 93,93 \\
\hline AEC_P & $\begin{array}{l}\text { Proporção de votos recebidos pelo } \\
\text { candidato Aécio Neves }\end{array}$ & 42,27 & 18,07 & 6,07 & 88,14 \\
\hline T_ANALF15M & Taxa de analfabetismo acima dos 15 anos & 16,15 & 9,84 & 0,95 & 44,40 \\
\hline T_SUPER25M & $\begin{array}{l}\text { Percentagem da população com } 25 \text { anos ou } \\
\text { mais com nível superior completo }\end{array}$ & 5,49 & 3,26 & 0,28 & 33,68 \\
\hline RDPC & Renda per capita - em R \$ de 2010 & 493,42 & 243,29 & 1,00 & $2.043,74$ \\
\hline T_DES18M & $\begin{array}{l}\text { Taxa de desemprego da população acima } \\
\text { dos } 18 \text { anos }\end{array}$ & 6,20 & 3,65 & 0,09 & 38,45 \\
\hline BOLSAF & $\begin{array}{l}\text { Número de famílias atendidas pelo bolsa } \\
\text { família em Setembro de } 2014 \text { em relação à } \\
\text { população total do município }\end{array}$ & 10,08 & 6,13 & 0,07 & 24,28 \\
\hline \multicolumn{6}{|c|}{ Variáveis Binárias } \\
\hline EXEC_EST & $\begin{array}{l}\text { Presença de Executivo estadual do mesmo } \\
\text { partido do presidente eleito - valor } 1 \text { caso } \\
\text { seja do mesmo partido e } 0 \text {, caso contrário }\end{array}$ & 0,40 & 0,49 & 0,00 & 1,00 \\
\hline EXEC_MUN & $\begin{array}{l}\text { Presença de Executivo municipal do mesmo } \\
\text { partido/coligação do presidente eleito - } \\
\text { valor } 1 \text { caso seja do mesmo partido e } 0 \text {, caso } \\
\text { contrário }\end{array}$ & 0,60 & 0,49 & 0,00 & 1,00 \\
\hline
\end{tabular}

Fonte: Tribunal Superior Eleitoral (TSE) para dados sobre proporção de votos, Atlas de Desenvolvimento Humano (Censo 2010) e Sistema de Benefícios ao Cidadão (SIBEC) da Caixa Econômica Federal para dados do Bolsa Família para 2014. Elaboração dos autores. 
Tabela A.2. Matriz de correlação entre as variáveis descritas na tabela

A.1

\begin{tabular}{|c|c|c|c|c|c|c|c|c|c|}
\hline & $\begin{array}{c}\text { Porc. } \\
\text { Dilma } \\
(\%)\end{array}$ & $\begin{array}{c}\text { Porc. } \\
\text { Aécio } \\
(\%)\end{array}$ & $\begin{array}{c}\text { Tx. } \\
\text { Analf. }\end{array}$ & $\begin{array}{l}\text { Tx. Ens. } \\
\text { Superior }\end{array}$ & $\begin{array}{l}\text { Renda } \\
\text { per } \\
\text { capita }\end{array}$ & $\begin{array}{c}\text { Tx. } \\
\text { Desemprego }\end{array}$ & $\begin{array}{l}\text { Bolsa } \\
\text { Família }\end{array}$ & $\begin{array}{c}\text { Executivo } \\
\text { Estadual }\end{array}$ & $\begin{array}{l}\text { Executivo } \\
\text { Municipal }\end{array}$ \\
\hline Porc. Dilma (\%) & 1 & $-0,72$ & 0,76 & $-0,55$ & $-0,75$ & 0,38 & 0,83 & 0,44 & $-0,01$ \\
\hline Porc. Aécio (\%) & $-0,72$ & 1 & $-0,67$ & 0,45 & 0,62 & $-0,34$ & $-0,70$ & $-0,44$ & 0,00 \\
\hline Tx. Analf. & 0,76 & $-0,67$ & 1 & $-0,61$ & $-0,81$ & 0,34 & 0,88 & 0,45 & $-0,04$ \\
\hline Tx. Ens. Superior & $-0,55$ & 0,45 & $-0,61$ & 1 & 0,77 & $-0,15$ & $-0,61$ & $-0,26$ & $-0,02$ \\
\hline Renda Per capita & $-0,75$ & 0,62 & $-0,81$ & 0,77 & 1 & $-0,38$ & $-0,86$ & $-0,43$ & 0,04 \\
\hline Tx. Desemprego & 0,38 & $-0,34$ & 0,34 & $-0,15$ & $-0,38$ & 1 & 0,42 & 0,24 & $-0,06$ \\
\hline Bolsa Família & 0,83 & $-0,70$ & 0,88 & $-0,61$ & $-0,86$ & 0,42 & 1 & 0,46 & $-0,02$ \\
\hline Executivo Estadual & 0,44 & $-0,44$ & 0,45 & $-0,26$ & $-0,43$ & 0,24 & 0,46 & 1 & $-0,04$ \\
\hline Executivo Municipal & $-0,01$ & 0,00 & $-0,04$ & $-0,02$ & 0,04 & $-0,06$ & $-0,02$ & $-0,04$ & 1 \\
\hline
\end{tabular}

Fonte: Elaboração dos autores.

Recebido em 07 de novembro de 2015

Aprovado em 25 de janeiro de 2016

\title{
Factors that contributed to the reelection of president Roussef
}

\begin{abstract}
This article aims to analyze, using spatial econometric methods, the main factors that led to the re-election of President DilmaRousseff in the presidential elections of 2014. In addition, it examines whether the presence of mayors and governors from the same party benefited his candidacy. The results indicate that the candidate received most votes in the least developed municipalities with lower per capita income, highest rate of illiteracy and unemployment, also being benefited by the presence of the governor of the same coalition. Another point discussed was from the Geographically Weighted Regression (GWR), the effect of the "Bolsa Família" program in each Brazilian municipality. The variable was significant statistically, mostly in the municipalities of South and Southeast.
\end{abstract}

Keywords: Presidential elections; Bolsa Familia Program; Spatial econometrics. 